\title{
Analisis Tebal Lapis Perkerasan Jalan dengan Meninjau Sifat Fisik Agregat Lapis Fondasi Bawah pada Ruas Jalan Sofi-Wayabula Pulau Morotai
}

\author{
NURUL FAUZIAH ENDAH NINGTYAS, SAMUN HARIS \\ Jurusan Teknik Sipil, Institut Teknologi Nasional, Bandung \\ Email: nurulfendah@gmail.com
}

\begin{abstract}
ABSTRAK
Jalan sebagai sarana penunjang transportasi darat memiliki peran penting untuk memenuhi kebutuhan manusia. Salah satu material penting dalam pembuatan jalan adalah agregat. Sifat fisik agregat menjadi salah satu faktor penentu tebal lapisan struktur perkerasan. Ruas jalan Sofi-Wayabula adalah ruas jalan nasional strategis di Pulau Morotai dengan menggunakan perkerasan lentur. Agregat yang digunakan untuk lapis fondasi bawah pada ruas jalan ini adalah kombinasi agregat Eks. Palu dengan agregat Eks. Morotai. Tujuan dari penelitian ini adalah untuk menganalisis tebal lapis fondasi bawah berdasarkan koefisien kekuatan relatif $\left(a_{3}\right)$ yang didapat dari nilai CBR kombinasi agregat Eks. Palu dengan agregat Eks. Morotai dan agregat Eks. Palu pada struktur perkerasan lentur. Dari hasil perhitungan metode Manual Perkerasan Jalan 2017 didapatkan tebal lapis fondasi bawah sebesar $15 \mathrm{~cm}$, bernilai sama, baik menggunakan kombinasi agregat Eks. Palu dengan agregat Eks. Morotai, maupun agregat Eks. Palu. Sedangkan, dengan menggunakan Pedoman Perkerasan Jalan Lentur 2011 didapat tebal lapis fondasi bawah sebesar 15,054 cm untuk kombinasi agregat Eks. Palu dengan agregat Eks. Morotai dan 14,608 cm untuk agregat Eks. Palu.
\end{abstract}

Kata Kunci: perkerasan lentur, koefisien kekuatan relatif, lapis fondasi bawah.

\begin{abstract}
Roads as a means of supporting land transportation have an important role to meet human needs. One of important material in road construction is aggregate. The aggregate physical properties become one of the determinants of the pavement thickness structure layer. The road segment of Sofi-Wayabula is a strategic national road in Morotai Island by using flexible pavement. The aggregate used for the subbase course of the road is combination of aggregate Ex. Palu with Ex. Morotai aggregate. The purpose of this research is to analyze the thickness of the sub-base course based on relative strength coefficient $\left(a_{3}\right)$ obtained from the value of CBR combination of aggregate Ex. Palu with Ex. Morotai aggregate and aggregate Ex. Palu on flexible pavement structures. From the calculation results of the Pavement Road Manual method 2017, the thick of sub-base course is $15 \mathrm{~cm}$, have equal value using the combination of Ex. Palu aggregate with Ex. Morotai aggregate or the Ex.Palu aggregate. Meanwhile, by using Flexible Road Pavement Guideline 2011 the thickness of the sub-base course is $15,054 \mathrm{~cm}$ for combination of Ex.Palu aggregate with Ex. Morotai aggregate and 14,608 cm for Ex.Palu.
\end{abstract}

Keywords: flexible pavement, relative strength coefficient, sub-base course. 


\section{PENDAHULUAN}

Seiring dengan perkembangan dan kemajuan zaman, manusia sering melakukan pergerakan dari suatu tempat ke tempat yang lain demi memenuhi kebutuhan. Sehingga dibutuhkan ketersediaan akan prasarana yang menunjang kegiatan tersebut, seperti jalan. Dengan adanya prasarana tersebut juga dapat menunjang suatu daerah agar lebih maju dari sebelumnya. Jalan harus didesain dengan baik, agar pengguna merasa aman dan nyaman ketika menggunakan. Salah satu material penting dalam pembuatan jalan adalah agregat. Tujuan dari penelitian ini adalah untuk merancang tebal lapis fondasi bawah berdasarkan koefisien kekuatan relatif $\left(a_{3}\right)$ yang didapat dari nilai CBR kombinasi agregat Eks. Palu dengan agregat Eks. Morotai dan agregat Eks. Palu pada struktur perkerasan. Untuk menghitung tebal perkerasan lentur menggunakan metode Manual Pekerasan Jalan 2017 dan metode Pedoman Perkerasan Jalan Lentur 2011 untuk lapis fondasi bawah.

\section{TINJAUAN PUSTAKA}

\subsection{Perkerasan Lentur}

Perkerasan lentur (flexible pavement) adalah perkerasan yang menggunakan aspal sebagai bahan pengikat. Pada umumnya perkerasan lentur baik digunakan untuk jalan yang melayani beban lalu lintas ringan sampai sedang, seperti jalan perkotaan, jalan dengan sistem utilitas terletak di bawah perkerasan jalan, perkerasan bahu jalan, atau perkerasan dengan konstruksi bertahap (Sukirman, 2010).

\subsection{Lapis Fondasi Bawah}

Salah satu fungsi lapis fondasi bawah (sub-base course) adalah sebagai bagian dari struktur perkerasan untuk mendukung dan menyebarkan beban kendaraan ke lapis tanah dasar. Lapis ini harus cukup stabil dan mempunyai CBR sama atau lebih besar dari $20 \%$, serta Indeks Plastis sama atau lebih kecil dari 10\% (Sukirman, 2010).

\subsection{Sifat Fisik Agregat}

Sifat agregat yang menentukan kualitasnya sebagai material perkerasan jalan adalah gradasi, kebersihan, kekerasan dan ketahanan agregat, bentuk butir, tekstur permukaan, porositas, kemampuan untuk menyerap air, berat jenis, dan daya ikat aspal dengan agregat. Sifat agregat yang menentukan tebal lapisan perkerasan adalah besar nilai CBR (Sukirman, 2016).

\subsection{Jenis Kendaraan}

Sistem klasifikasi kendaraan dinyatakan dalam Pedoman Survei Pencacahan Lalu Lintas (Pd T19-2004-B) seperti pada Gambar 1.

\begin{tabular}{|c|c|c|c|c|}
\hline Golongan & Kelompok jenis kendaraan & Jenis kendaraan & $\begin{array}{l}\text { Konfigurasi } \\
\text { sumbu }\end{array}$ & Kode \\
\hline 1 & Sepeda motor, kendaraan roda- 3 & (2) $(\mathrm{H}+1)$ & & \\
\hline 2 & Sedan, jeep, station wagon & 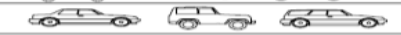 & 虽吕 & 1.1 \\
\hline 3 & Angkutan penumpang sedang & कित क्ष & 虽 吕 & 1.1 \\
\hline 4 & Pick up, micro truk dan mobil hantaran & ब삼 & 嵒 & 1.1 \\
\hline $5 a$ & Bus kecil & पून्व & 点 高 & 1.1 \\
\hline $5 b$ & Bus besar & 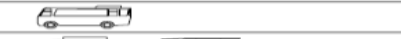 & 吕曾 & 1.2 \\
\hline $6 a$ & Truk ringan 2 sumbu & क्म & 号孚 & 1.1 \\
\hline $6 \mathrm{~b}$ & Truk sedang 2 sumbu & घh न घhत & 呂 & 1.2 \\
\hline $7 a$ & Truk 3 sumbu & क्ष & 吕霓官 & 1.2 .2 \\
\hline $7 b$ & Truk gandengan & का & 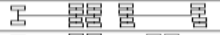 & $1.2 .2-2.2$ \\
\hline $7 c$ & Truk semitrailer & FL क्ष & 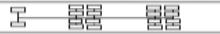 & 1.2 .2 .2 .2 \\
\hline 8 & Kendaraan tidak bermotor & बत्ठ केष्ठ म्5 & & ate Wi \\
\hline
\end{tabular}

Gambar 1. Golongan dan kelompok jenis kendaraan (Sumber: Kementerian Pekerjaan Umum dan Perumahan Rakyat, 2004) 


\subsection{Faktor Pertumbuhan Lalu Lintas}

Faktor pertumbuhan lalu lintas berdasarkan data-data pertumbuhan series (historical growth data) atau formulasi korelasi dengan faktor pertumbuhan lain yang berlaku. Besar nilai faktor pertumbuhan lalu lintas dapat dilihat pada Tabel 1 dan untuk faktor pengali pertumbuhan lalu lintas dihitung dengan Persamaan 1 sebagai berikut:

Tabel 1. Faktor Laju Pertumbuhan Lalu Lintas (i) (\%)

\begin{tabular}{lcccc} 
& Jawa & Sumatera & Kalimantan & Rata-rata Indonesia \\
\hline Arteri dan perkotaan & 4,80 & 4,83 & 5,14 & 4,75 \\
\hline Kolektor rural & 3,50 & 3,50 & 3,50 & 3,50 \\
\hline Jalan desa & 1,00 & 1,00 & 1,00 & 1,00 \\
\hline
\end{tabular}

(Sumber: Kementerian Pekerjaan Umum dan Perumahan Rakyat, 2017)

$$
R=\frac{(1+0,01 i)^{U R}-1}{0,001 i}
$$

halmana:

$R=$ faktor pengali pertumbuhan lalu lintas kumulatif,

$i=$ laju pertumbuhan lalu lintas tahunan [\%] Tabel 1,

$U R \quad=$ umur rencana [tahun].

\subsection{Lajur Rencana}

Lajur rencana adalah salah satu lajur lalu lintas dari suatu ruas jalan yang menampung lalu lintas kendaraan niaga (truk dan bus) paling besar. Untuk jalan dua arah, faktor distribusi arah (DD) umumnya diambil 0,50. Sedangkan, faktor distribusi jalan yang ditunjukkan pada Tabel 2 .

Tabel 2. Faktor Distribusi Lajur (DL)

\begin{tabular}{cc}
\hline $\begin{array}{c}\text { Jumlah } \\
\text { Lajur } \\
\text { Setiap } \\
\text { Arah }\end{array}$ & Kendaraan Niaga pada Lajur Desain \\
\hline 1 & (\% Terhadap Populasi Kendaraan Niaga) \\
\hline 2 & 100 \\
\hline 3 & 80 \\
\hline 4 & 60 \\
\hline
\end{tabular}

(Sumber: Kementerian Pekerjaan Umum dan Perumahan Rakyat, 2017)

2.7 Perencanaan Tebal Perkerasan Lentur Metode Manual Perkerasan Jalan 2017 Berdasarkan metode Manual Perkerasan Jalan 2017, perhitungan beban sumbu standar kumulatif atau Cumulative Equivalent Single Axle Load (CESAL) dengan VDF masing-masing kendaraan niaga ditentukan menggunakan Persamaan 2 sebagai berikut: 


$$
E S A_{T H-1}=\left(\Sigma L H R_{I K} * V D F_{I K}\right) * 365 * D_{D} * D_{L} * R
$$

halmana:

$E S A_{T H-1}=$ kumulatif lintasan Sumbu Standar Ekuivalen (Equivalent Standard Ax/e) pada tahun pertama,

$L H R_{J K} \quad=$ lintas harian rata-rata tiap jenis kendaraan niaga [satuan kendaraan perhari],

$V D F_{J K} \quad=$ faktor Ekuivalen Beban (Vehicle Damage Factor) tiap jenis kendaraan niaga (Tabel 3),

$D_{D} \quad=$ faktor distribusi arah $(0,5)$,

$D_{L} \quad$ = faktor distribusi lajur (Tabel 2),

$R=$ = faktor pengali pertumbuhan lalu lintas kumulatif dengan Persamaan 1.

Setelah besar nilai $\mathrm{CESA}_{5}$ telah diperoleh maka dapat menentukan tebal lapisan struktur perkerasan lentur pada bagan desain seperti pada Tabel 4 dan Tabel 5.

Tabel 3. Nilai VDF Masing - Masing Jenis Kendaraan Niaga

\begin{tabular}{ccc}
\hline Jenis kenderaan & \multicolumn{2}{c}{ Bali, Nusa Tenggara, Maluku dan Papua } \\
\cline { 2 - 3 } & $\begin{array}{c}\text { VDF } \mathbf{5} \\
\text { Beban Aktual }\end{array}$ & $\begin{array}{c}\text { VDF } \mathbf{5} \\
\text { Normal }\end{array}$ \\
\hline 5B & 1,0 & 1,0 \\
\hline $6 \mathrm{~A}$ & 0,5 & 0,5 \\
\hline $6 \mathrm{~B}$ & 4,0 & 3,0 \\
\hline 7A2 & 9,7 & 6,0 \\
\hline 7C1 & 11,9 & 8,0 \\
\hline
\end{tabular}

(Sumber: Kementerian Pekerjaan Umum dan Perumahan Rakyat, 2017)

Tabel 4. Bagan Desain Perkerasan dengan HRS

\begin{tabular}{lcc}
$\begin{array}{c}\text { Kumulatif Beban Sumbu 20 Tahun pada } \\
\text { Lajur Rencana (10 }\end{array}$ CESA5) & FF1 $<\mathbf{0 , 5}$ & $\mathbf{0 , 5} \leq \mathbf{F F 2}<\mathbf{4 , 0}$ \\
\hline \multicolumn{1}{c}{ Jenis permukaan } & $\begin{array}{c}\text { HRS atau Penetrasi } \\
\text { Macadam }\end{array}$ & HRS \\
\hline Struktur Perkerasan & \multicolumn{2}{c}{ Tebal Lapisan [mm] } \\
\hline HRS WC & 50 & 30 \\
\hline HRS Base & - & 35 \\
\hline LFA Kelas A & 150 & 250 \\
\hline LFA Kelas A atau LFA Kelas B dengan kerikil & 150 & 125 \\
\hline alam atau lapis distabilisasi dengan CBR $>10 \%$ & 150 & \\
\hline
\end{tabular}

(Sumber: Kementerian Pekerjaan Umum dan Perumahan Rakyat, 2017) 
Tabel 5. Bagan Desain Lapis Perkerasan Aspal dengan Lapis Fondasi Berbutir

\begin{tabular}{|c|c|c|c|c|c|c|c|c|c|}
\hline & FFF1 & FFF2 & FFF3 & FFF4 & FFF5 & FFF6 & FFF7 & FFF8 & FFF9 \\
\hline \multicolumn{5}{|c|}{ Solusi yang dipilih } & \multicolumn{5}{|c|}{ Lihat Catatan 2} \\
\hline $\begin{array}{c}\text { Kumulatif } \\
\text { Beban Sumbu } \\
20 \text { Tahun pada } \\
\text { Lajur Rencana } \\
\text { (106 ESA5) }\end{array}$ & $\begin{array}{l}\mathbf{N} \\
\mathbf{v}\end{array}$ & $\begin{array}{l}+ \\
\mathbf{1} \\
\mathbf{\Lambda}\end{array}$ & $\begin{array}{l}\hat{1} \\
\dot{\lambda}\end{array}$ & $\begin{array}{l}0 \\
\rightarrow 1 \\
1 \\
\hat{\Lambda}\end{array}$ & $\begin{array}{l}\text { 오 } \\
\text { ' } \\
\text { - } \\
1\end{array}$ & 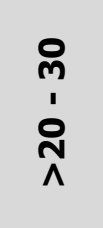 & 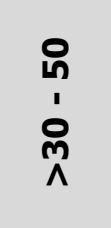 & 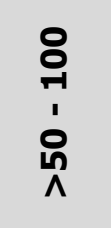 & $\begin{array}{l}8 \\
\stackrel{2}{1} \\
1 \\
8 \\
\circ \\
1\end{array}$ \\
\hline \multicolumn{10}{|c|}{ KETEBALAN LAPIS PERKERASAN [mm] } \\
\hline AC WC & 40 & 40 & 40 & 40 & 40 & 40 & 40 & 40 & 40 \\
\hline$A C B C$ & 60 & 60 & 60 & 60 & 60 & 60 & 60 & 60 & 60 \\
\hline AC Base & 0 & 70 & 80 & 105 & 145 & 160 & 180 & 210 & 245 \\
\hline LPA Kelas A & 400 & 300 & 300 & 300 & 300 & 300 & 300 & 300 & 300 \\
\hline
\end{tabular}

(Sumber: Kementerian Pekerjaan Umum dan Perumahan Rakyat, 2017)

\subsection{Perhitungan Tebal Struktur berdasarkan Pedoman Pekerasan Jalan Lentur 2011}

Berdasarkan Pedoman Perkerasan Jalan Lentur 2011, untuk lalu lintas ringan dengan jumlah repetisi beban lalu lintas $\leq 1$ juta ESA dapat digunakan jenis semi struktural. Tebal lapis permukaan adalah $5 \mathrm{~cm}$ dengan menggunakan HRS WC. Untuk mengitung tebal lapis fondasi (base) menggunakan Persamaan $\mathbf{3}$ dan untuk tebal lapis fondasi bawah (sub-base) menggunakan Persamaan 4 sebagai berikut:

$$
\begin{gathered}
\text { T base }=1,9126(\ln L)+15,645 \\
\text { T sub- base }=3,6708(\ln L)-4,1875 \mathrm{CBR}+51,046
\end{gathered}
$$

halmana:

$L=$ repetisi beban lalu lintas [juta ESA],

CBR $\quad=$ CBR sub-grade [\%],

T base $\quad=$ tebal Lapis Fondasi Agregat Kelas A (CBR 90\%), [cm],

$T$ sub-base $=$ tebal Lapis Fondasi Agregat Kelas B (CBR 60\%), [cm].

\subsection{Nilai Structural Number(SN) Berdasarkan Metode AASTHO}

Nilai Structural Number $(S N)$ adalah angka yang menunjukkan jumlah tebal lapis perkerasan. Nilai Structural Number $(S N)$ dalam metode AASHTO dapat dihitung dengan menggunakan Persamaan 5 sebagai berikut:

$$
S N=a_{1} D_{1}+a_{2} D_{2}+a_{3} D_{3}
$$

halmana:

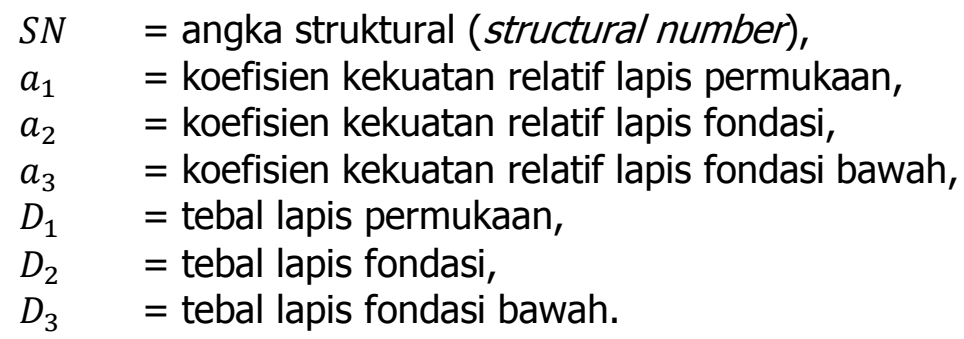


Nilai koefisien kekuatan relatif lapis permukaan dapat dilihat pada Tabel 6. Untuk lapis fondasi dan lapis fondasi bawah berdasarkan Gambar 2 dan Gambar 3.

Tabel 6. Koefisien Kekuatan Relatif Lapis Permukaan $\left(a_{1}\right)$

\begin{tabular}{ccc} 
Jenis Perkerasan & $\begin{array}{c}\text { Modulus Tipikal } \\
(\mathbf{M P a})\end{array}$ & $\begin{array}{c}\text { Koefisien } \\
\text { Relatif }\left(\boldsymbol{a}_{\mathbf{1}}\right)\end{array}$ \\
\hline HRS WC & 800 & 0,28 \\
\hline HRS BC & 900 & 0,28 \\
\hline
\end{tabular}

(Sumber: Kementerian Pekerjaan Umum, 2012)

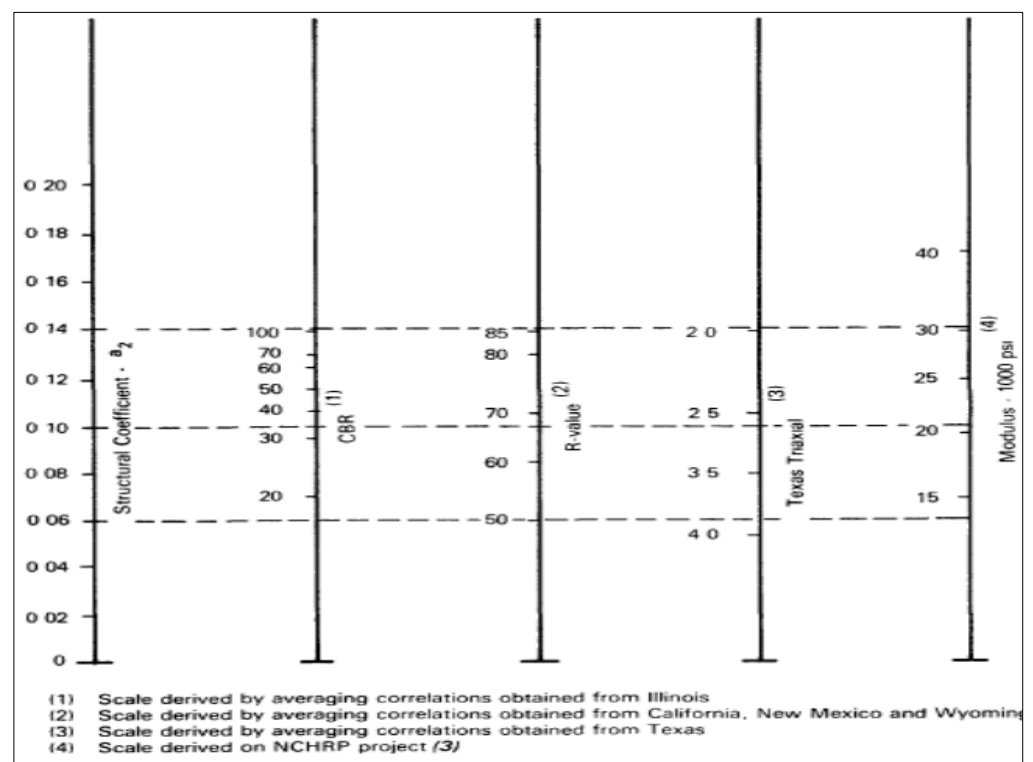

Gambar 2. Koefisien kekuatan relatif, $\left(a_{2}\right)$

(Sumber: AASHTO, 1993)

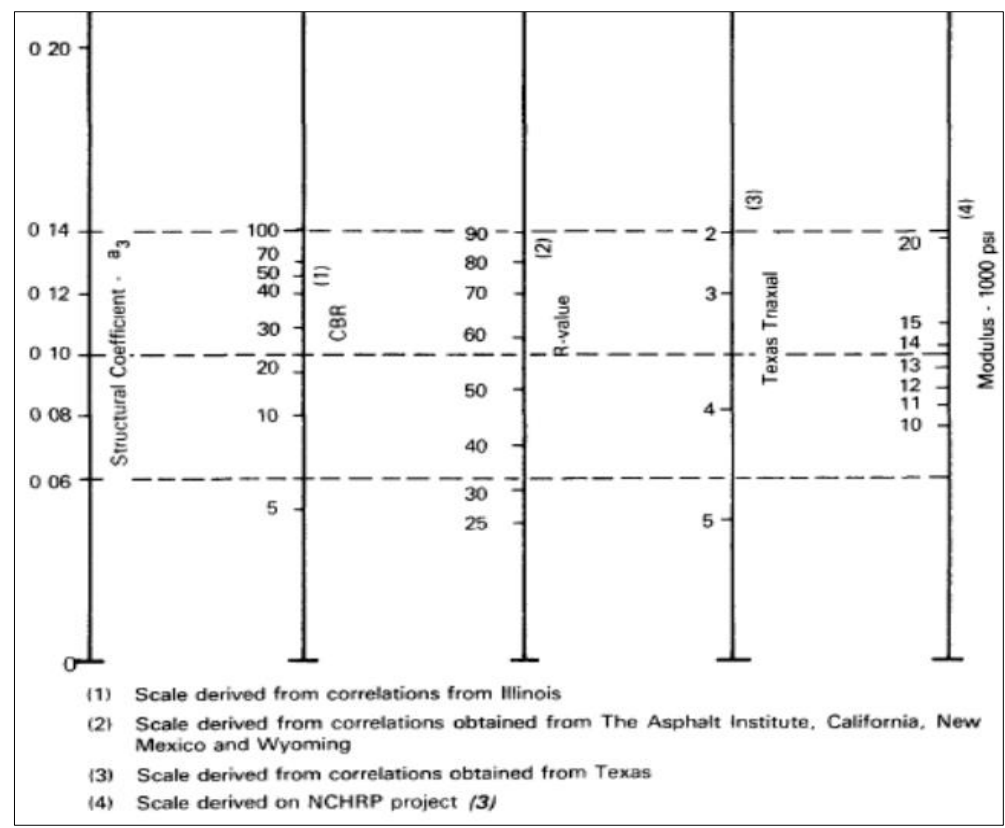

Gambar 3. Koefisien kekuatan relatif, $\left(a_{3}\right)$ (Sumber: AASHTO, 1993) 


\section{METODE PENELITIAN}

Penelitian ini akan dilakukan dengan prosedur seperti pada Gambar 4. Data sekunder diperoleh dari PT. Laosindo Pratama dan Penataan Ruang Provinsi Sulawesi Tengah. Data sekunder meliputi data CBR tanah dasar dan data pengujian sifat fisik agregat Eks. Palu dan kombinasi agregat Eks. Palu dengan agregat Morotai. Sedangkan data primer, yaitu data lalu lintas harian.

Metode yang digunakan dalam penelitian ini adalah metode Manual Perkerasan Jalan 2017 untuk tebal lapisan struktur perkerasan dan untuk tebal lapis fondasi bawah berdasarkan nilai CBR agregat menggunakan metode Pedoman Perkerasan Jalan Lentur 2011 dengan koefisien kekuatan relatif mengacu pada metode AASHTO 1993.

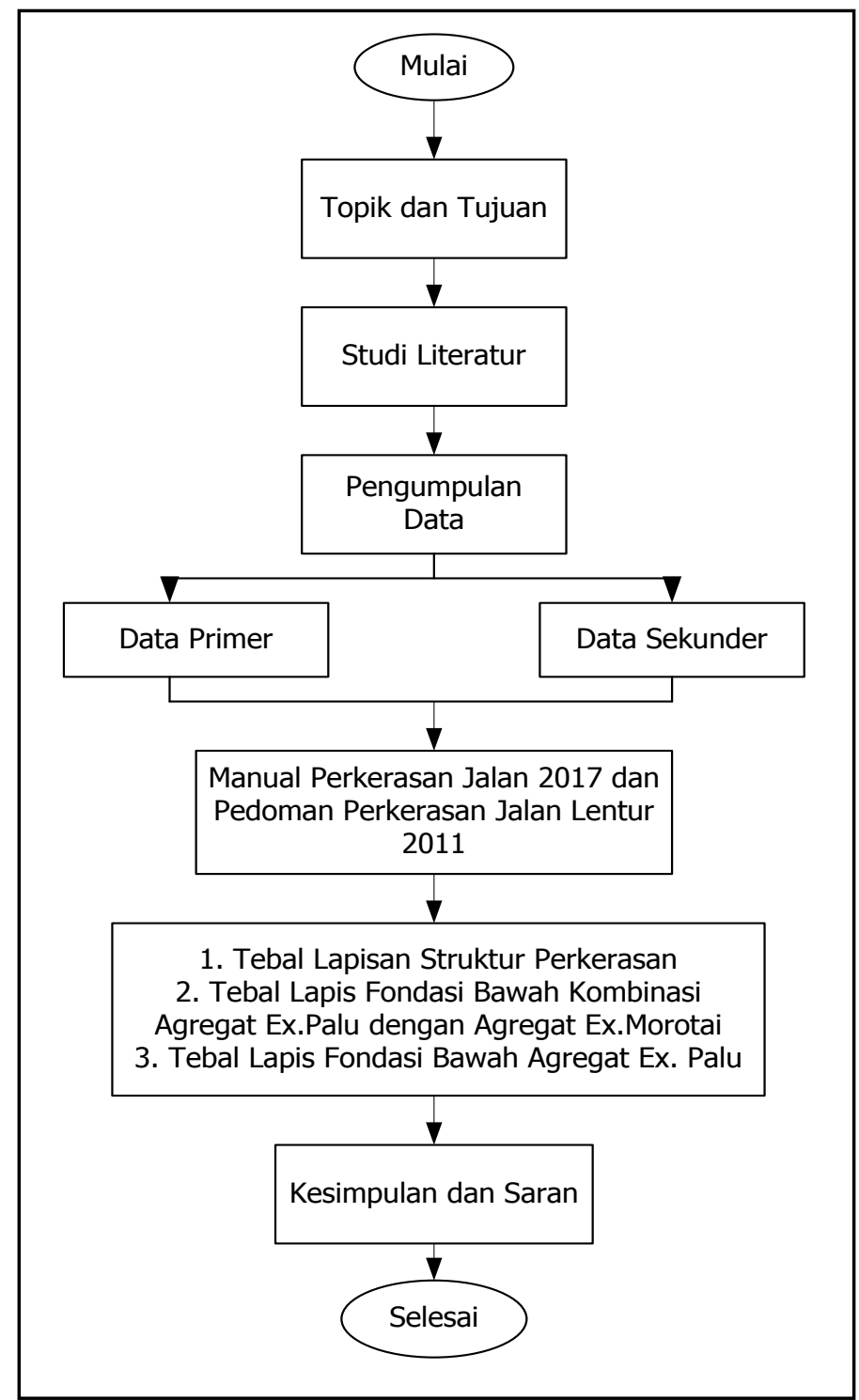

Gambar 4. Prosedur penelitian 


\section{ANALISIS DATA}

\subsection{Data Penelitian}

Data hasil pengujian dapat dilihat pada Tabel 7. Spesifikasi yang digunakan adalah Spesifikasi Umum Bina Marga Tahun 2010 Revisi 3 untuk agregat kelas B. Tabel 8 memperlihatkan data LHR tahun 2018.

Tabel 7. Data Pengujian Agregat

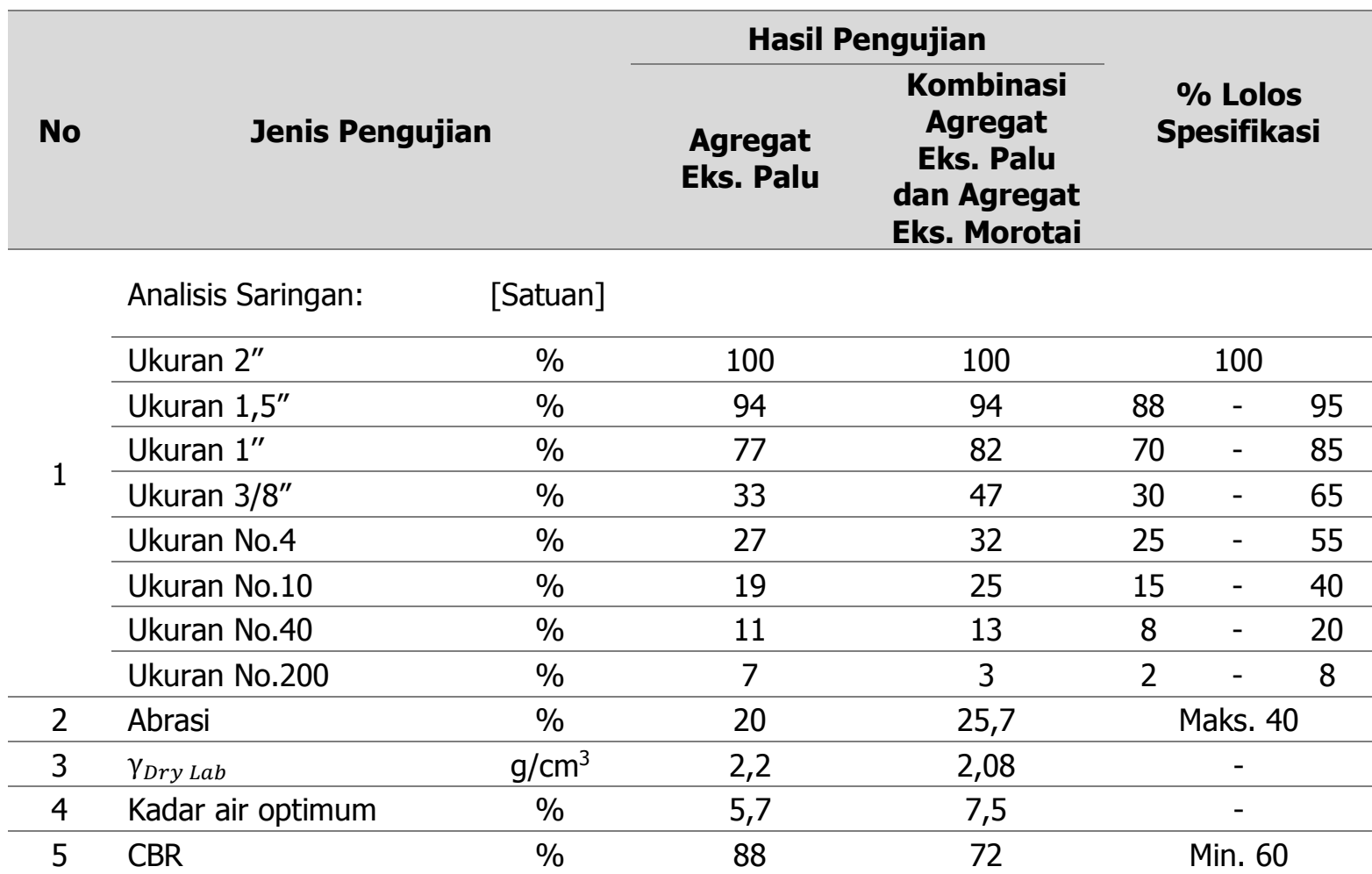

(Sumber: PT. Laosindo Pratama, 2017, dan Dinas Bina Marga dan Penataan Ruang Provinsi Sulawesi Tengah, 2018)

Tabel 8. Data LHR Tahun 2018

\begin{tabular}{ccc}
\hline Golongan & Jenis Kendaraan & $\begin{array}{c}\text { LHR 2018 } \\
\text { [Kend/hari/2 arah }]\end{array}$ \\
\hline 1 & Sepeda Motor & 164 \\
\hline 2 & Sedan, Jeep, St. Wagon & 102 \\
\hline 3 & Pick-up, Combi & 16 \\
\hline 4 & Micro Truck, Mobil Hantaran & 8 \\
\hline $5 a$ & Bus Kecil & 2 \\
\hline $5 b$ & Bus Besar & 4 \\
\hline $6 a$ & Truk 2 Sumbu, 4 roda & 14 \\
\hline $6 b$ & Truk 2 Sumbu, 6 roda & 8 \\
\hline
\end{tabular}

4.2 Perencanaan Tebal Perkerasan Lentur Metode Manual Perkerasan Jalan 2017 Tabel 8 memperlihatkan besar nilai CESA dengan umur rencana 20 tahun, pertumbuhan lalu lintas 3,5\% dan nilai VDF. Besar nilai CESA dihitung dengan menggunakan Persamaan 2. Tabel 10 memperlihatkan tebal lapis perkerasan yang diperoleh berdasarkan nilai CESA5, yaitu sebesar 0,139 juta ESA5. 
Tabel 9. Perhitungan Nilai CESA

\begin{tabular}{|c|c|c|c|c|c|c|c|}
\hline \multirow[b]{2}{*}{$\begin{array}{c}\text { Jenis } \\
\text { Kendaraan }\end{array}$} & \multirow{2}{*}{$\begin{array}{l}\text { Lintas } \\
\text { Harian } \\
\text { Rata- } \\
\text { rata (2 } \\
\text { Arah) }\end{array}$} & \multirow[b]{2}{*}{$\begin{array}{l}\text { LHR } \\
2018\end{array}$} & \multirow[b]{2}{*}{$\begin{array}{l}\text { LHR } \\
2024\end{array}$} & \multirow[b]{2}{*}{$\begin{array}{c}\text { VDF } 5 \\
\text { FAKTUAL }\end{array}$} & \multirow[b]{2}{*}{$\begin{array}{c}\text { VDF } 5 \\
\text { NORMAL }\end{array}$} & \multirow{2}{*}{$\begin{array}{c}\text { ESA5 } \\
\text { ('18-'20) }\end{array}$} & \multirow{2}{*}{$\begin{array}{c}\text { ESA5 } \\
\text { ('21-'38) }\end{array}$} \\
\hline & & & & & & & \\
\hline $\begin{array}{c}\text { Mobil } \\
\text { penumpang } \\
\text { dan } \\
\text { kendaraan } \\
\text { ringan lain }\end{array}$ & 292 & 292 & 347 & - & - & - & - \\
\hline $5 B$ & 4 & 4 & 4 & 1 & 1 & 1463 & 14105 \\
\hline $6 \mathrm{~A}$ & 14 & 14 & 15 & 0,5 & 0,5 & 2559 & 24683 \\
\hline $6 B$ & 8 & 8 & 9 & 4 & 3 & 11700 & 84628 \\
\hline \multicolumn{6}{|c|}{ Jumlah ESA5 } & 15812 & 123416 \\
\hline \multicolumn{6}{|c|}{ CESA5 ('18-'38) } & \multicolumn{2}{|c|}{139.138} \\
\hline
\end{tabular}

Tabel 10. Tebal Lapisan Struktur Perkerasan

\begin{tabular}{cc}
\hline Struktur Perkerasan & Tebal Lapisan $[\mathbf{m m}]$ \\
\hline HRS WC & 50 \\
\hline HRS BASE & - \\
\hline LPA Kelas A & 150 \\
\hline LPB Kelas B & 150 \\
\hline
\end{tabular}

\subsection{Perhitungan Tebal Lapisan Struktur Perkerasan Berdasarkan Pedoman Perkerasan Jalan Lentur 2011}

Dengan nilai CESA sebesar 0,139 juta ESA dan CBR sub-grade adalah 6\% didapat tebal lapis perkerasan seperti pada Tabel 11. Nilai koefisien kekuatan relatif untuk $a_{1}$ dari Tabel 6, $a_{2}$ dari Gambar 2 dan $a_{3}$ dari Gambar 3.

Tabel 11. Tebal Lapisan Struktur Perkerasanan Koefisien Kekuatan Relatif

\begin{tabular}{lcc}
\multicolumn{1}{c}{ Struktur Perkerasan } & Tebal Lapisan $[\mathbf{c m}]$ & $\begin{array}{c}\text { Koefisien Kekuatan Relatif } \\
\text { (a) }\end{array}$ \\
\hline HRS WC & 5 & 0,28 \\
\hline Lapis Fondasi (CBR 90\%) & 11,873 & 0,134 \\
\hline Lapis Fondasi Bawah (CBR 60\%) & 18,681 & 0,128
\end{tabular}

Dari Tabel 11 diperoleh nilai SN adalah 2,119 inci dengan menggunakan Persamaan 5. Karena tebal lapis fondasi pada metode ini berbeda dengan Manual Perkerasan Jalan 2017 sehingga menggunakan Persamaan 5, untuk mencari tebal lapis fondasi bawah $\left(D_{3}\right)$ dengan parameter koefisien kekuatan relatif (a) sesuai seperti pada Tabel $\mathbf{1 1}$ dan untuk tebal lapis permukaan $\left(D_{1}\right)$ dan tebal lapis fondasi $\left(D_{2}\right)$ sesuai seperti Tabel 10. Tabel 12 berikut ini memperlihatkan tebal lapisan struktur perkerasan yang akan digunakan untuk mencari tebal lapis fondasi bawah berdasarkan nilai CBR agregat. 
Tabel 12. Tebal Lapisan Struktur Perkerasan

\begin{tabular}{lc}
\multicolumn{1}{c}{ Struktur Perkerasan } & Tebal Lapisan $[\mathbf{c m}]$ \\
& \\
\hline HRS WC & 5 \\
\hline Lapis Fondasi (CBR 90\%) & 15 \\
\hline Lapis Fondasi Bawah (CBR 60\%) & 15,407 \\
\hline
\end{tabular}

\subsection{Perhitungan Tebal Lapis Fondasi Bawah Berdasarkan Nilai CBR}

Dari data pengujian diperoleh nilai CBR untuk kombinasi agregat Eks. Palu dan agregat Morotai sebesar $72 \%$. Dengan menggunakan Gambar 3, nilai Koefisien kekuatan relatif $\left(a_{3}\right)$ adalah sebesar 0,131 . Tebal lapis fondasi bawah dapat dihitung dengan mengacu pada Persamaan 5.

$\left(D_{3} * a_{3}\right)$ agregat $60 \%=\left(D_{3} * a_{3}\right)$ agregat $72 \%$,

$(15,407 * 0,128)=\left(D_{3} * 0,131\right)$

$D_{3}$ agregat $72 \%=15,054 \mathrm{~cm}$.

Dari data pengujian diperoleh nilai CBR untuk agregat Eks. Palu sebesar $88 \%$. Dengan menggunakan Gambar 3, nilai Koefisien kekuatan relatif $\left(a_{3}\right)$ adalah sebesar 0,135. Tebal lapis fondasi bawah dapat dihitung dengan menggunakan Persamaan 5.

$\left(D_{3} * a_{3}\right)$ agregat $60 \%=\left(D_{3} * a_{3}\right)$ agregat $72 \%$,

$(15,407 * 0,128)=\left(D_{3} * 0,135\right)$

$D_{3}$ agregat $88 \%=14,608 \mathrm{~cm}$.

Tabel 13 berikut ini memperlihatkan perbedaan tebal lapis fondasi bawah berdasarkan koefisien kekuatan relatif.

Tabel 13. Perbedaan Tebal Lapis Fondasi Bawah

\begin{tabular}{|c|c|c|c|c|}
\hline \multirow[b]{2}{*}{$\begin{array}{l}\text { Lapisan Struktur } \\
\text { Perkerasan }\end{array}$} & \multicolumn{2}{|c|}{ Manual Perkerasan Jalan 2017} & \multicolumn{2}{|c|}{$\begin{array}{c}\text { Pedoman Perkerasan Jalan } \\
\text { Lentur } 2011\end{array}$} \\
\hline & $\begin{array}{c}\text { Kombinasi } \\
\text { agregat } \\
\text { Eks. Palu } \\
\text { dengan } \\
\text { Agregat } \\
\text { Eks. Morotai }\end{array}$ & $\begin{array}{c}\text { Agregat Eks. } \\
\text { Palu } \\
\text { (CBR 88\%) }\end{array}$ & $\begin{array}{l}\text { Kombinasi } \\
\text { Agregat Eks. } \\
\text { Palu dengan } \\
\text { Agregat Eks. } \\
\text { Morotai }\end{array}$ & $\begin{array}{c}\text { Agregat } \\
\text { Eks. Palu } \\
\text { (CBR 88\%) }\end{array}$ \\
\hline Lapis Permukaan [cm] & 5 & 5 & 5 & 5 \\
\hline Lapis Fondasi [cm] & 15 & 15 & 15 & 15 \\
\hline Lapis Fondasi Bawah $[\mathrm{cm}]$ & 15 & 15 & 15,054 & 14,608 \\
\hline
\end{tabular}




\section{KESIMPULAN}

Dari hasil perencanaan tebal lapis fondasi bawah yang telah dilakukan, dengan metode Manual Perkerasan Jalan 2017 didapat tebal lapis fondasi bawah sebesar $15 \mathrm{~cm}$, baik menggunakan kombinasi agregat Eks. Palu dengan agregat Eks. Morotai, maupun agregat Eks. Palu. Sedangkan, dengan metode Manual Perkerasan Jalan Lentur 2011 didapat tebal lapis fondasi bawah sebesar 15,054 cm menggunakan kombinasi agregat Eks. Palu dengan agregat Eks. Morotai dan 14,608 cm menggunakan agregat Eks. Palu. Sehingga, agregat Eks. Palu lebih menguntungkan dengan nilai CBR $88 \%$.

\section{DAFTAR RUJUKAN}

American Association of State Highway and Transportation Officials (AASHTO). (2012). tentang Guide for Design of Pavement Structure. Washington DC: AASHTO.

Departemen Pemukiman dan Prasarana Wilayah. (2004). Survei Pencacahan Lalu Lintas dengan cara Manual. Jakarta: Direktorat Jenderal Bina Marga.

Kementerian Pekerjaan Umum dan Perumahan Rakyat. (2017). Manual Perkerasan Jalan, Direktorat Jenderal Bina Marga. Jakarta: Kementerian Pekerjaan Umum dan Perumahan Rakyat.

Kementerian Pekerjaan Umum. (2012). Manual Desain Perkerasan Lentur. Jakarta: Direktorat Jenderal Bina Marga.

PT. Laosindo Pratama. (2017). Material Pengujian Kombinasi Agregat Eks. Palu dengan Agregat Morotai. Morotai: PT. Laosindo Pratama.

Sukirman, S. (2016). Beton Aspal Campuran Panas. Bandung: Institut Teknologi Nasional.

Sukirman, S. (2010). Perencanaan Tebal Struktur Perkerasan Lentur. Bandung: NOVA. 